\title{
The Diagnostic and Therapeutic Value of the Detection of Serum Amyloid A and C-Reactive Protein in Infants with Rotavirus Diarrhea
}

\author{
Yin-Jiang Lv \\ Qi-Lei Hu \\ Rong Huang \\ Liang Zhang \\ Li-Feng Wu \\ Shui Fu
}

Department of Clinical Laboratory, The First People's Hospital of Yuhang District, Hangzhou, Hangzhou, Zhejiang, 3III00, People's Republic of China
Correspondence: Shui Fu

Department of Clinical Laboratory, The First People's Hospital of Yuhang District, Hangzhou, No. 369 Yingbin Road of

Nanyuan Street, Yuhang District,

Hangzhou, 31I100, People's Republic of China

Tel +8657I 89369404

Email fushuiolo@I63.com
Objective: This study explores the significance of serum amyloid A (SAA), C-reactive protein (CRP), and white blood cell (WBC) in the diagnosis and treatment of diarrhea in infants.

Methods: Specimens were collected from 126 children with diarrhea and 66 healthy children undergoing health examination. According to the results of stool culture and rotavirus (RV) antigen, these children were divided into three groups: rotavirus group (70 cases), bacterial infection (56 cases), and control groups (66 cases). On the fourth day of admission, children in the RV group underwent stool culture again. Based on the subsequent results, they were further divided into two groups, ie, no secondary bacterial infection and secondary bacterial infection groups. The levels of RV antigen, bacterial antigen, SAA, CRP, and WBC were detected in all children. Then, ROC curve analysis was performed to determine the diagnostic efficacy of SAA, CRP and WBC.

Results: The levels of SAA, CRP, and WBC for the RV group were lower than those of the bacterial infection group, but higher compared with the control group $(\mathrm{P}<0.05)$. The diagnostic efficacy of SAA was higher than that of CRP and WBC, with the area under the curve of $0.876,0.803$, and 0.765 , respectively. The positive and negative predictive values, specificity, and sensitivity of SAA were slightly better compared with CRP and WBC. The SAA, CRP, and WBC levels of children with a bacterial infection in the RV group on the fourth and seventh days after admission were also significantly higher compared with children without bacterial infection.

Conclusion: Serum amyloid A, CRP, and WBC levels had a high value in the differential diagnosis of infantile diarrhea. As such, they can be used in the early diagnosis and curative efficacy assessment of children with diarrhea.

Keywords: group A rotavirus, serum amyloid A, C-reactive protein, white blood cell, diagnostic efficacy

\section{Introduction}

"Infantile diarrhea" refers to a group of digestive tract syndromes caused by multiple pathogens and factors. It is characterized by an increase in stool frequency and a change in stool characteristics and is one of the most common ailments among infants in China. Rotavirus (RV) and bacteria are the main pathogens that cause infantile diarrhea. ${ }^{1-3}$ Because the treatment of viral and bacterial diarrhea is quite different, the correct differential diagnosis is a key factor in the diagnosis and treatment of infantile diarrhea. In this context, microbiology is the gold standard 
indicator used for etiology diagnosis. However, its detection cycle requires at least $48 \mathrm{~h}$ or longer, making it difficult to meet clinical needs. ${ }^{4,5}$ It is thus important for clinical diagnosis and treatment to explore highly efficient detection indicators in the diagnosis and treatment of infantile diarrhea.

Existing literature reports the diagnostic value of white blood cell (WBC), C-reactive protein (CRP), interleukin-6 (IL-6), and procalcitonin in infantile diarrhea. However, its diagnostic efficacy requires further improvement. Additionally, the reported studies represent primarily horizontal research, and the role of indicators in the diagnosis and treatment of RV diarrhea is not clear. Serum amyloid A (SAA) protein is an acute-phase reaction protein produced by hepatocytes that are secreted into serum. When the body is infected or injured, this protein can rapidly increase (approximately 1000 times in 4-6 h), and rapidly decrease to a normal level once the antigen in the body has been resolved. ${ }^{6-9}$ During respiratory virus infection, the levels of SAA in symptomatic influenza patients are significantly increased, even in infants within 2 months of age. ${ }^{10}$ The measurement of SAA is also used for the early diagnosis of hand-foot-and-mouth disease. ${ }^{11}$ Serum amyloid A protein is significantly increased in viral infectious diseases; as such, it can be used as a sensitivity indicator for the diagnosis of such infections. This study evaluates the application value of SAA in the diagnosis and treatment of RV patients and provides a reliable theoretical basis for the diagnosis and treatment of RV enteritis.

\section{Materials and Methods Specimen Source}

The stool culture results of 178 hospitalized infants with diarrhea, 66 healthy infants, and infants with RV infection on the fourth day of admission from October 2019 to December 2019 were collected. A diagnosis was made based on the Expert Consensus on the Principles of Diagnosis and Treatment of Diarrhea in Children. ${ }^{12}$ The feces of all infants were inoculated in $<1$ hour. Patients were excluded if they met the following criteria: 1) did not underwent pathogen examination; 2) not detected with pathogen; 3) had a fever 3 days before admission. On the first, fourth, and seventh days after admission, blood samples were collected from ill and healthy infants (see the experimental grouping section for more detail) and placed in an ethylenediamine tetraacetic acid anticoagulant tube for the analysis of SAA and CRP, as well as blood examination, and detected within 2 hours. Secondary infection was defined as positive bacterial culture on the 4th day after admission.

\section{Instruments and Consumables}

ECC, a Vibrio chromogenic plate, hematoxylin and eosin, and 0157 chromogenic plate were purchased from Zhengzhou Biocell Biotechnology Co., Ltd. (China), while blood plate, and stainless steel and McConkey plates were provided by Zhengzhou Autobio Co., Ltd. (China). Rotavirus was detected using the PAGE method. The reagents used in this method were prepared by our laboratory. ${ }^{8}$ Serum amyloid A protein and CRP were detected by immunoanalyzer (Jet-iStar3000; Hangzhou Joinstar Biomedical Technology Co., Ltd., China) and supporting reagents.

\section{Procedures}

\section{Fecal Culture}

In strict accordance with the National Regulations for Clinical Laboratory Practice (fourth edition), appropriate amounts of feces were inoculated in different media and/or Petri dishes for culture and identification.

\section{Detection of Serum Amyloid A Protein and C-Reactive Protein}

Using the Jet-iStar3000, background tests and internal quality control were effected before daily use. The immunoanalyzer could be used only after the test results had been qualified. Detection was performed on the instruments strictly according to their ascribed operational procedures.

\section{Experimental Grouping}

Among 178 cases of diarrhea, 40 were not detected with pathogens and 3 experienced fever $\geq 3$ days before admission and. They were excluded from this study. In the remaining 135 cases, 9 were tested positive for both RV and bacteria; 56 cases carried a single bacterial pathogen; 70 cases were positive for single RV. Those tested for both RV and bacteria were excluded from the study. Finally, the RV group included 70 infants (34 males, 36 females) with a median age of 26 months (range: 2 months -4 years). There were 56 cases in the bacterial infection group ( 29 males, 27 females) with a median age of 25 months (range: 2 months -4 years). In this group, there were 18 cases of Streptococcus pneumoniae, 13 cases of Haemophilus influenzae, 10 


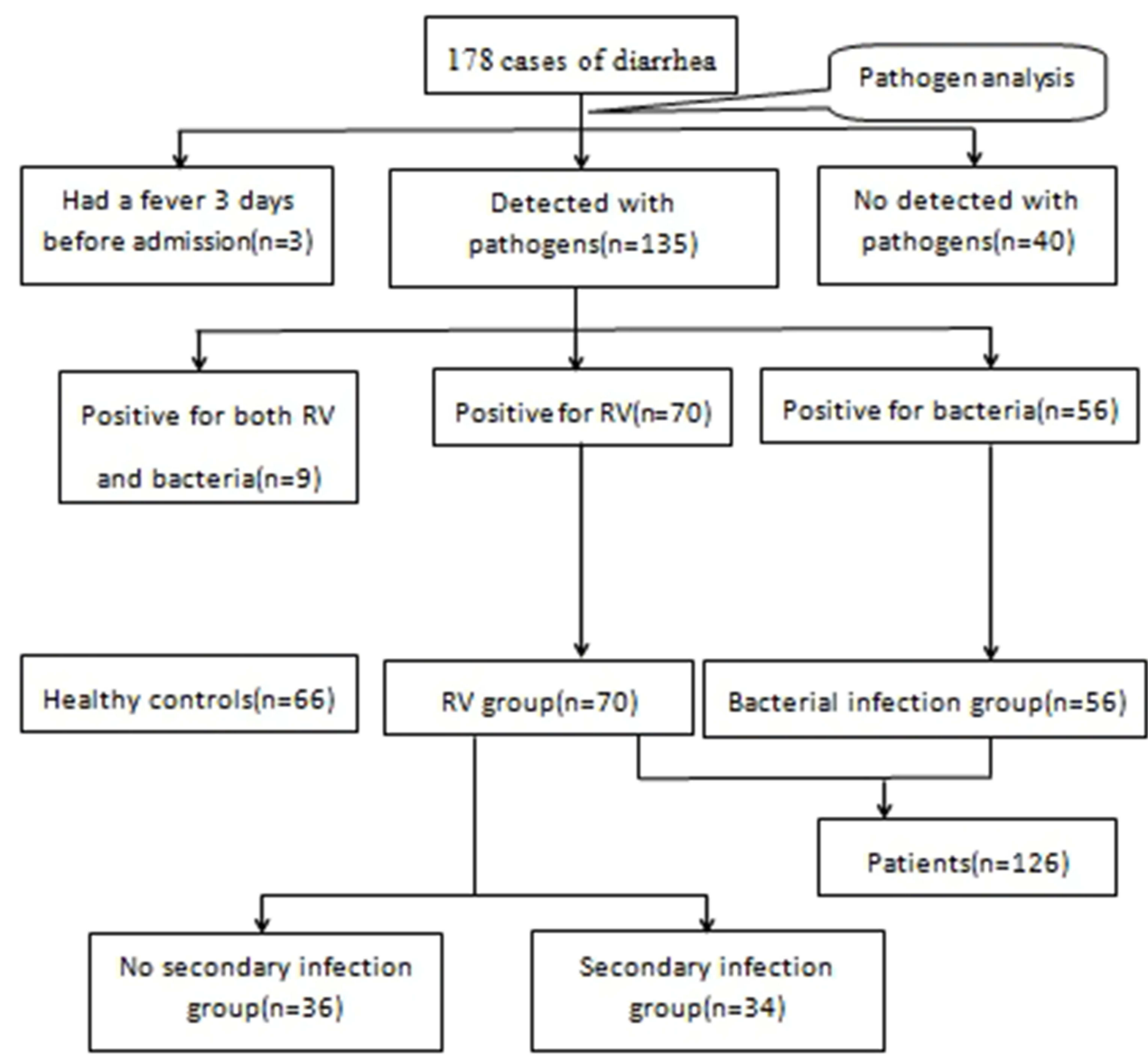

Figure I A flow chart of the selection of cases.

cases of Staphylococcus aureus, 8 cases of Klebsiella pneumoniae, 5 cases of Branhamella catarrhalis, and 2 cases of Escherichia coli), there were 66 cases in the control group (33 males, 33 females) with a median age of 26 months (range: 2 months -4 years). No pathogens were detected in the healthy children (Figure 1).

\section{Treatment and Outcomes}

Patients infected with RV were given anti-influenza virus drugs (ribavirin) and nutritional support. The bacterial infection group was given antibiotic treatment based on the results of bacterial culture and nutritional support. All patients had no clinical symptoms, such as fever, on the 7th day of admission.

\section{Statistical Analysis}

Data were analyzed using statistical software SPSS Statistics 26.0. The relevant data were tested for normality. Normally distributed data were expressed as mean \pm standard deviation $(\mathrm{X} \pm \mathrm{SD})$, and compared between two groups using an independent sample $t$-test.
Intergroup comparison was conducted using analysis of variance or Chi-square test. $\mathrm{P}<0.05$ was considered statistically significant.

\section{Results}

\section{Test Results of 4 Indexes in 3 Groups}

The test results for four indicators in three groups (WBC, $\mathrm{CRP}$, and SAA) in the bacterial infection group were significantly higher than those in the RV and control groups. In the RV group were higher than those in the control group, and the differences were all statistically significant (Table 1).

\section{Comparison of the Positive Rates of White Blood Cells, C-Reactive Protein, and Serum Amyloid A Protein on the Day of Onset}

Among 126 infants with diarrhea, the WBC of 83 infants was higher than $10 \times 10^{9} / \mathrm{L}$, and the positive rate was $65.87 \%$. The level of CRP was higher than the reference 
Table I Comparison of WBC, CRP and SAA Among the Three Groups at Admission

\begin{tabular}{|l|c|c|c|c|}
\hline Group & Number of Case & WBC $\left(\times 10^{9} / \mathbf{L}\right)$ & CRP (mg/L) & SAA (mg/L) \\
\hline Rotavirus group & 70 & $7.59 \pm 2.38$ & $21.63 \pm 11.42$ & $79.36 \pm 32.56$ \\
Bacterial infection group & 56 & $15.62 \pm 6.31$ & $48.62 \pm 21.36$ & $316.80 \pm 107.02$ \\
Control group & 66 & $5.28 \pm 2.01$ & $3.56 \pm 1.28$ & $3.85 \pm 1.09$ \\
$F$ value & - & 26.48 & 28.69 & 63.29 \\
$P$ value & - & 0.006 & 0.004 & 0.001 \\
\hline
\end{tabular}

Abbreviations: $F$, statistical value of difference analysis; WBC, white blood cell; CRP, C-reactive protein; SAA, Serum amyloid A.

Table 2 Comparison of the Positive Rates of WBC, CRP and SAA on the Day of Onset of All Patients

\begin{tabular}{|l|c|c|c|c|c|}
\hline Item & $\begin{array}{c}\text { Number } \\
\text { of Case } \\
(\mathbf{n})\end{array}$ & $\begin{array}{c}\text { Positive } \\
\text { Cases } \\
(\mathbf{n})\end{array}$ & $\begin{array}{c}\text { Positive } \\
\text { Rate (\%) }\end{array}$ & $\begin{array}{c}\chi^{2} \\
\text { value }\end{array}$ & $\boldsymbol{P}$ value \\
\hline SAA & 126 & 116 & 92.06 & $4.331^{\Delta}$ & $0.037^{\Delta}$ \\
CRP & 126 & 104 & 82.54 & $8.293^{*}$ & $0.004^{*}$ \\
WBC & 126 & 83 & 65.87 & $26.020^{\#}$ & $<0.001^{\#}$ \\
\hline
\end{tabular}

Notes: ${ }^{\triangle}$ SAA compared to CRP; *CRP compared with WBC; ${ }^{\#}$ SAA compared to WBC.

upper limit ( $8 \mathrm{mg} / \mathrm{L})$ in 104 infants, and the positive rate was $82.54 \%$. Serum amyloid A level was higher than normal levels $(10 \mathrm{mg} / \mathrm{L})$ in 116 infants, and the positive rate was $92.06 \%$. The positive rate of SAA was compared with those of CRP and $\mathrm{WBC}$, and the positive rate of CRP was compared with that of WBC; the differences were all statistically significant $(\mathrm{P}<0.05)$. Detailed results are shown in Table 2.

\section{Changes in Three Indicators in the} Treatment Process for Children with RV Infants who showed positive bacterial culture on the 4th day after admission were categorized into the secondary infection group, while those showed negative culture were included in the no secondary infection group. In the no secondary infection group, on the fourth and seventh days after admission, the three indicators were lower than those at admission, and they returned to normal on day seven. In the secondary infection group, these indicators were significantly increased on the fourth day of admission. Furthermore, there were significant differences in the three indicators on the fourth and seventh days after admission between the secondary and the nonsecondary infection group (Table 3 ).

\section{The Diagnostic Efficacy of Serum Amyloid} A, C-Reactive Protein, and White Blood Cells in the Diagnosis of Rotavirus

After analyzing the efficacy of SAA $(<10 \mathrm{mg} / \mathrm{L})$, CRP $(<8 \mathrm{mg} / \mathrm{L})$, and WBC $\left(4-10 \times 10^{9} / \mathrm{L}\right)$, the following conclusions were made. The efficacy indexes of SAA were higher compared with $\mathrm{CRP}(\mathrm{P}<0.05)$ and WBC $(\mathrm{P}<0.05)$, and $\mathrm{CRP}$ indexes were higher than those of WBC $(\mathrm{P}<0.05)$. The ROC curve showed that SAA, CRP, and

Table 3 Comparison of Detection Results of Bacterial Infection in the Rotavirus Infection Group

\begin{tabular}{|c|c|c|c|c|c|c|c|c|c|}
\hline \multirow[t]{2}{*}{ Item } & \multirow[t]{2}{*}{ Day 0} & \multicolumn{4}{|l|}{ Day 4} & \multicolumn{4}{|l|}{ Day 7} \\
\hline & & $\begin{array}{l}\text { No Secondary } \\
\text { Infection Group }\end{array}$ & $\begin{array}{l}\text { Secondary } \\
\text { Infection } \\
\text { Group }\end{array}$ & $t$ value & $P$ value & $\begin{array}{l}\text { No Secondary } \\
\text { Infection Group }\end{array}$ & $\begin{array}{l}\text { Secondary } \\
\text { Infection } \\
\text { Group }\end{array}$ & $t$ value & $P$ value \\
\hline $\begin{array}{l}\text { WBCX } \\
\left(10^{9} / L\right)\end{array}$ & $\begin{array}{l}7.59 \\
\pm 2.38\end{array}$ & $5.86 \pm 2.13$ & $13.98 \pm 3.26$ & 7.56 & 0.023 & $5.36 \pm 1.98$ & $8.36 \pm 2.41$ & 4.06 & 0.031 \\
\hline $\begin{array}{l}\text { CRP } \\
(\mathrm{mg} / \mathrm{L})\end{array}$ & $\begin{array}{l}21.63 \\
\pm 11.42\end{array}$ & $8.52 \pm 2.14$ & $53.62 \pm 18.67$ & 12.36 & 0.001 & $4.32 \pm 1.05$ & $|8.25 \pm 5.9|$ & 11.83 & 0.002 \\
\hline $\begin{array}{l}\text { SAA } \\
(\mathrm{mg} / \mathrm{L})\end{array}$ & $\begin{array}{l}79.36 \\
\pm 32.56\end{array}$ & $6.92 \pm 1.99$ & $189.23 \pm 38.26$ & 15.52 & 0.001 & $5.03 \pm 1.12$ & $86.59 \pm 18.26$ & 12.39 & 0.001 \\
\hline
\end{tabular}

Notes: No complicated bacterial infection group $(n=36)$; complicated bacterial infection group $(n=34)$.

Abbreviations: WBC, white blood cell; CRP, C-reactive protein; SAA, Serum amyloid A. 


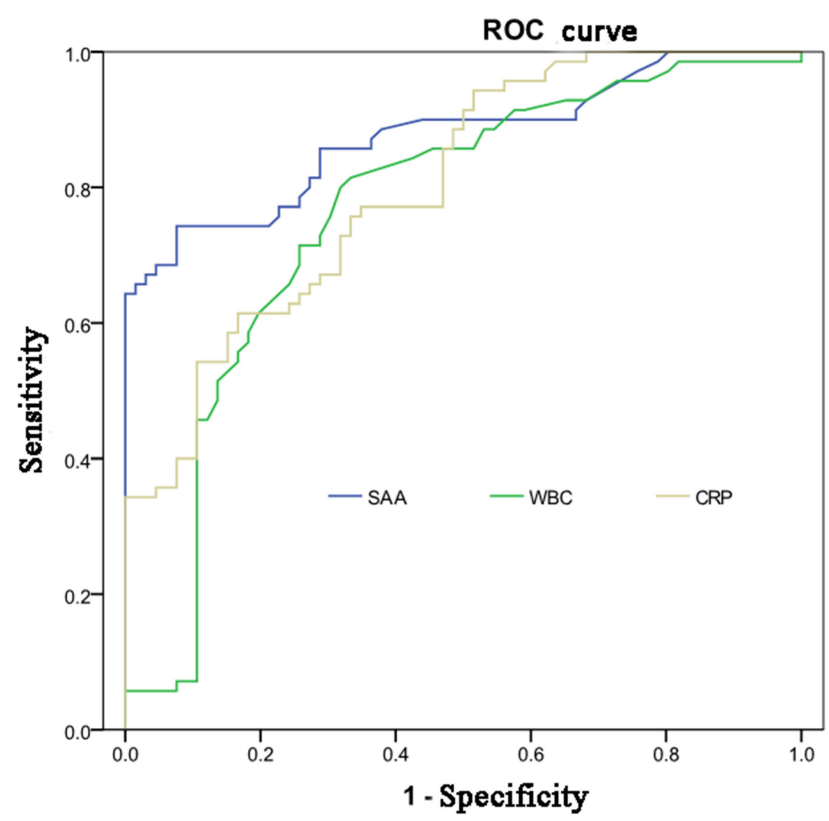

Figure 2 SSA, CRP and WBC ROC curve.

WBC had diagnostic value for rotavirus and their effectiveness was gradually reduced. The area under the curve of SAA, CRP, and WBC were 0.876, 0.803, and 0.765, respectively (Figure 2 and Table 4).

\section{Discussion}

"Diarrhea" represents a group of intestinal tract infectious diseases characterized by high incidence rate and widespread prevalence; its propagation speed is fast, its incidence rate among infants is very high, and it is one of the main causes of death among newborns. ${ }^{13,14}$ There are many types of pathogenic microorganisms in infantile diarrhea including bacteria, viruses, protozoa, and fungi. More than half of cases, however, are caused by group-A RV. Antibiotics are the main treatment method for bacterial diarrhea. However, $\mathrm{RV}$ enteritis is not an indication for prescribing antibiotics because of the different treatment methods that are applied for these two diarrhea types. Accordingly, early differential diagnosis of diarrhea in infants is paramount. Current microbiology monitoring takes too long, however, and it is difficult to provide effective experimental results early. ${ }^{15}$ Therefore, in the early diagnosis and treatment of infants with diarrhea, it is of great significance that monitoring is strengthened and that observations of dynamic changes related to indicators in infants with diarrhea and the analysis of clinical data be effected promptly.

The results of this study revealed that levels of SAA, CRP, and WBC were significantly higher in the bacterial infection group than in the RV and control groups. In the RV group, these indicators only slightly exceeded the upper limit of their respective reference ranges and were higher than in the control group. After analyzing the efficacy of SAA, CRP, and WBC, it was concluded that these three indicators present good diagnostic efficacy. For SAA, diagnostic efficacy was higher compared with CRP and WBC, and the diagnostic efficacy of CRP was higher than WBC. This may be closely related to the short half-life of SAA and its significant increase when the body is stimulated by bacteria, viruses, mycoplasma, chlamydia, and other antigens (SAA increases rapidly by approximately 1000 times in 5-6 $\mathrm{h}$, and its half-life is $50 \mathrm{~min}$, while CRP increases rapidly after 5-8 $\mathrm{h}$ and reaches a peak at $24 \mathrm{~h}$, with a half-life of approximately $6 \mathrm{~h}$ ). Due to the different diagnostic thresholds, the efficiency of ROC curve analysis is lower than that of respective reference intervals. Our study only analyzed the diagnostic efficacy of SAA, CRP, and WBC alone. Whether the combination of these parameters would yield higher diagnostic efficacy warrants further investigation.

Although SAA has good diagnostic efficacy in the differential diagnosis of infantile diarrhea, research in this regard is lacking. Technology requires further improvement; many hospitals (particularly primary hospitals, where most infants with diarrhea are first diagnosed) have only just begun promoting research in this area. In addition, CRP and WBC are classic emergency factors that can quickly and accurately be detected in laboratory settings. For infants with diarrhea, it is recommended that CRP and WBC be detected first for preliminary

Table 4 Value of SAA, CRP and WBC in the Diagnosis of Rotavirus

\begin{tabular}{|l|l|l|l|l|l|l|}
\hline Item & $\begin{array}{l}\text { Sensitivity } \\
\text { (\%) }\end{array}$ & $\begin{array}{l}\text { Specificity } \\
(\%)\end{array}$ & $\begin{array}{l}\text { Positive Predictive } \\
\text { Value (\%) }\end{array}$ & $\begin{array}{l}\text { Negative Predictive } \\
\text { Value (\%) }\end{array}$ & $\begin{array}{l}\text { Youden Index } \\
\text { (\%) }\end{array}$ & $\begin{array}{l}\text { Concordance index } \\
\text { (\%) }\end{array}$ \\
\hline SAA & 87.14 & 93.94 & 93.85 & 93.94 & 81.08 & 90.44 \\
CRP & 81.43 & 90.91 & 90.48 & 90.91 & 72.34 & 86.03 \\
WBC & 67.14 & 81.82 & 79.66 & 81.82 & 48.96 & 74.26 \\
\hline
\end{tabular}


differential diagnosis at an early stage; following on, SAA should be detected in a conditional laboratory.

An existing study revealed that CRP and $\mathrm{WBC}$ are useful indicators in the differential diagnosis of bacterial and viral infantile diarrhea. The current study further consolidated these findings by analyzing the dynamic changes in three indicators among 70 infants with RV diarrhea during hospitalization. Since the course of RV diarrhea is generally five-to-eight days, fecal cultures were performed again in the middle stage of the disease (approximately the fourth day after admission). In addition, SAA, CRP, and WBC levels were detected again on the fourth and seventh days after admission. On the fourth day after admission, the results of three tests showed a significant decrease in the levels of the three indicators, which were close to normal ranges in infants with RV diarrhea and without bacterial infection. Indicator levels continued to increase in infants with RV diarrhea with a bacterial infection, and the differences between the two were statistically significant. On the seventh day of admission, the results of the three indicator tests returned to normal ranges in infants with RV diarrhea without bacterial infection; these were also significantly decreased compared with those on the fourth day after admission in infants with RV diarrhea with a bacterial infection. This is closely related to the selflimitation of RV diarrhea itself, and the overall improvement of medical diagnosis and treatment levels. Therefore, SAA, CRP, and WBC levels can be used as differential diagnostic criteria, and can also be employed as monitoring indexes for judging the diagnosis and treatment of infants with diarrhea. That is, the above indicators should be monitored during the treatment of infants with RV diarrhea when there is a significant increase or no significant improvement in their clinical condition. The occurrence of complications should also be anticipated. Based on these conditions, the causes should be actively investigated, and targeted prevention and treatment should be carried out to avoid worsening of the disease. The strength of the current study is that we addressed the dynamic changes in SAA, CRP, and WBC levels in the diagnosis and treatment of children with RV diarrhea. However, it should be noted that the present study had a small sample size; therefore, additional prospective studies are anticipated to further confirm the results presented herein. Also, whether SAA, CRP, and WBC could be used as predictors of complications, treatment effectiveness, and antibiotics resistance in children with RV diarrhea warrants further investigation.

\section{Conclusion}

In summary, SAA and CRP are reliable laboratory indicators for the diagnosis and treatment of RV diarrhea in infants. The diagnostic efficiency of SAA is higher than that of CRP; however, combining the two laboratory indicators can further improve the differential diagnosis and determination of RV diarrhea in infants. The combined application of the two laboratory indicators can enable early diagnosis of RV diarrhea in infants and can help to evaluate the clinical treatment effect, thereby creating a foundation for the clinical diagnosis and treatment of $\mathrm{RV}$ diarrhea.

\section{Ethics Approval}

This study was conducted in accordance with the declaration of Helsinki. This study was conducted with approval from the Ethics Committee of The First People's Hospital of Yuhang District, Hangzhou. A parent or legal guardian of the infants provided informed consent.

\section{Disclosure}

All authors declare that the work is original and has not been submitted or published elsewhere. None of the authors have any financial disclosure or conflict of interest.

\section{References}

1. Weldegebriel G, Mwenda JM, Chakauya J, et al. Impact of rotavirus vaccine on rotavirus diarrhoea in countries of East and Southern Africa. Vaccine. 2018;36(47):7124-7130. doi:10.1016/j. vaccine.2017.10.050

2. Sack GH Jr. Serum amyloid A -a review. Mol Med. 2018;124(1):46.

3. Palihawadana P, Kang G, Navaratnasingam J, et al. Rotavirus infection among hospitalized children under five years of age with acute watery diarrhea in Sri Lanka. Vaccine. 2018;36(51):7846-7850. doi:10.1016/j. vaccine. 2018.03 .062

4. Stankovic Stojanovic K, Hentgen V, Fellahi S, et al. Concordance between CRP and SAA in familial Mediterranean fever during attack-free period: a study of 218 patients. Clin Biochem. 2017;50(45):206-209. doi:10.1016/j.clinbiochem.2016.11.008

5. Laboratory Medicine Committee of Chinese Association of Integrated Traditional and Western Medicine. The clinical application of serum amyloid A in infectious diseases. Chin J Lab Med. 2019;42 (3):186-192.

6. Wakai M, Hayashi R, Tanaka S, et al. Serum amyloid A is a better predictive biomarker of mucosal healing than $\mathrm{C}$-reactive protein in ulcerative colitis in clinical remission. BMC Gastroenterol. 2020;20 (1):85. doi:10.1186/s12876-020-01229-8

7. Long A, Nolen-Walston R. Equine inflammatory markers in the Twenty-First Century: a focus on serum amyloid A. Vet Clin North Am Equine Pract. 2020;36(1):147-160. doi:10.1016/j. cveq.2019.12.005

8. Huang ZX. Fundamentals of Medical Virology and Experimental Techniques. Beijing: Science Press; 1990:633-636. 
9. Ennival I, Gangstar L, Lei L, Jiang JJ. The value of SAA and CRP combined with WBC in the diagnosis of infectious diseases in children. J Guizhou Med Univ. 2019;44(6):721-724.

10. Whicher JT, Brand KH, Zomer A, et al. Prospective observational study in two Dutch hospitals to assess the performance of inflammatory plasma markers to determine disease severity of viral respiratory tract infections in children. BMJ Open. 2017;7(6):e014596. doi:10.1136/bmjopen-2016-014596

11. Liu J, Huang P, He Y, et al. Serum amyloid A and clusterin as potential predictive biomarkers for severe hand, foot and mouth disease by 2D-DIGE proteomics analysis . PLoS One. 2014;9(9): e108816. doi:10.1371/journal.pone.0108816

12. Gastroenterology Group of Pediatrics Branch of Chinese Medical Association, Infection Group of Pediatrics Branch of Chinese Medical Association, Editorial Committee of Chinese Journal of Pediatrics. Expert consensus on the principles of diagnosis and treatment of diarrheal diseases in children. Chin J Pediatr. 2009;47 (8):634-636
13. Herlice Do Nascimento Veras H, Medeiros PHQS, Ribeiro SA, et al. Campylobacter jejuni virulence genes and immune-inflammatory biomarkers association with growth impairment in children from Northeastern Brazil. Eur J Clin Microbiol Infect Dis. 2018;37 (10):2011-2020. doi:10.1007/s10096-018-3337-0

14. Ibrahim KA, Abdel-Wahab AA, Ibrahim AS. Diagnostic value of serum procalcitonin levels in children with meningitis: a comparison with blood leukocyte count and C-reactive protein. J Pak Med Assoc. 2011;61(4):346-351.

15. Fellahi S, Béraud L, Capeau J, et al. Validation of the usual values provided by a supplier without access to a control population: example of serum amyloid A. Ann Biol Clin (Paris). 2019;77(3):255-259. doi:10.1684/abc.2019.1439
International Journal of General Medicine

\section{Publish your work in this journal}

The International Journal of General Medicine is an international, peer-reviewed open-access journal that focuses on general and internal medicine, pathogenesis, epidemiology, diagnosis, monitoring and treatment protocols. The journal is characterized by the rapid reporting of reviews, original research and clinical studies
Dovepress

across all disease areas. The manuscript management system is completely online and includes a very quick and fair peer-review system, which is all easy to use. Visit http://www.dovepress.com/ testimonials.php to read real quotes from published authors. 